\title{
An alternative method for measuring velocities in open-channel flows: perfomance evaluation of a Pitot tube compared to an acoustic meter
}

\author{
Um método alternativo para medição de velocidades em escoamentos livres: \\ avaliação de desempenho de um tubo de Pitot em comparação a um medidor acústico
}

\author{
Arlan Scortegagna Almeida ${ }^{1}$ and Vladimir Caramori Borges de Souza ${ }^{1}$ \\ ${ }^{1}$ Universidade Federal de Alagoas, Maceió, AL, Brazil \\ E-mails: arlanscort@gmail.com (ASA),vcaramori@yahoo.com (VCBS)
}

Received: July 14, 2016 - Revised: October 24, 2016 - Accepted: November 21, 2016

\begin{abstract}
Hydrometric measurements undertaken in channels with high velocities are conditioned to the particularities of the flow, which is often characterized by instantaneous fluctuations and disturbances on the free surface. In such cases, the uncertainties associated with velocity fluctuations exceed the precision offered by the instruments that are employed in conventional techniques. A reasonable accuracy of the results is therefore sufficient to accomplish the objective of the measurements. The use of devices based on Pitot's principle in fast open-channel flows could be an effective alternative to conventional velocity meters. This study aimed to develop a Pitot tube in its simplest configuration and evaluate its performance in a laboratory channel at velocities ranging from 0.2 to $2.0 \mathrm{~m} / \mathrm{s}$. The uncertainties in the static and total head readings were propagated to the output velocities, showing that the device built has the potential for measurements over $1.2 \mathrm{~m} / \mathrm{s}$, but it is not recommended for low velocities $(<0.6 \mathrm{~m} / \mathrm{s})$. The results were compared to those taken using an Acoustic Doppler Velocimeter (ADV). The instantaneous velocity readings indicated uncertainties of the same order of magnitude in both instruments. The differences between the mean velocities measured by the Pitot tube and the ADV were restricted to an agreement range of 15\%, which is expected to be gradually reduced with further increase in flow velocity. The results showed the similar performances of both devices regarding the higher velocity estimates. Therefore, velocity meters should be developed to employ Pitot devices as an alternative method in high-velocity open-channel flows.
\end{abstract}

Keywords: Hydrometry; Open channel flow; Differential head meters; Pitot tube.

\section{RESUMO}

Aplicações de hidrometria em canais com altas velocidades estão sujeitas às condições do fluxo, que geralmente é caracterizado por flutuações instantâneas e perturbações na superfície livre. Nesses casos, as incertezas associadas às flutuações de velocidade superam a precisão oferecida pelos instrumentos empregados nas técnicas convencionais. Uma exatidão razoável dos resultados é, portanto, suficiente para atender ao objetivo das medições. O uso de dispositivos baseados no princípio de Pitot em escoamentos rápidos pode ser uma alternativa eficaz ao uso dos medidores de velocidade convencionais. Este estudo teve por objetivo confeccionar um tubo de Pitot em sua configuração mais simples e avaliar seu desempenho em um canal experimental para velocidades variando no intervalo de 0,2 a 2,0 m/s. As incertezas nas leituras de carga estática e de carga total foram propagadas para as velocidades estimadas, mostrando que o dispositivo construído tem potencial para medições acima de 1,2 m/s, mas não é recomendado para baixas velocidades $(<0,6 \mathrm{~m} / \mathrm{s}$ ). Os resultados foram comparados com um Velocímetro Acústico de Efeito Doppler (ADV). As leituras de velocidade instantânea indicaram incertezas de mesma magnitude em ambos os instrumentos. As diferenças entre as velocidades médias estimadas com o tubo de Pitot e com o ADV foram limitadas a uma margem de concordância de $15 \%$ que tende a ser reduzida com o aumento da velocidade local. Os resultados demonstraram um desempenho similar do tubo de Pitot frente ao medidor acústico no que se refere às velocidades mais altas. Medidores baseados no princípio de Pitot apresentam-se, portanto, como alternativa para o emprego nos escoamentos livres de alta velocidade.

Palavras-chave: Hidrometria; Escoamentos livres; Medidores de carga de velocidade; Tubo de Pitot. 


\section{INTRODUCTION}

Modern open-channel flow meters are available in several technologies (e.g., mechanical, electromagnetic, and acoustic). These meters are the basic instrument used in the velocity-area method, which is the most common direct technique used to estimate the discharge of streams and channels. The discharge is calculated through the discrete integration of the product between a crosssectional area that is normal to the flow and a point velocity that is considered representative of the cross section (LE COZ et al., 2012). Thus, open-channel flow meters are essentially velocity meters that operate according to different physical principles.

Among the most frequently used instruments are mechanical current meters, the principle of operation of which is based on the proportionality between flow velocity and the resulting angular velocity of the meter rotor (WMO, 2010a). This category includes vertical-axis Price current meters, which are widely employed in North America, and horizontal axis meters, which are commonly employed in Brazil. These instruments have some disadvantages, such as the need for periodic calibration in specialized laboratories. In addition, because of the inertia of the rotating components, the efficiency with which the meters translate linear velocity into angular velocity affects their ability to measure accurately in pulsating flows (FULFORD, 1995).

Acoustic Doppler current meters, such as ADVs and ADCPs, use a sophisticated and recent technology. They perform accurate readings at a frequency that enables an instantaneous response to turbulent fluctuations in velocity (VOULGARIS; TROWBRIDGE, 1998). These instruments contain an acoustic transmitter that emits a signal of a known frequency. The signal is reflected in particles of the flow at different relative velocities, and then it undergoes a phase change that is caused by the Doppler shift. The magnitude of the phase change, which is proportional to the fluid velocity, is measured by the acoustic receiver. This method is efficient, but it is expensive. It also is affected by the inherent limitations of the Doppler Effect. The quality of the measurements depends on the presence of particles suspended in the flow, and it can be affected by the interference caused by acoustic boundaries (REHMEL, 2007).

Both methods are usually employed in hydrometric determinations because they produce accurate measurements. However, in certain applications, such as urban drainage channels, there are considerable risks associated with operation and equipment loss, which are caused by the drag and degradation of water quality. In such cases, it may also be desirable to perform continuous measurements at several spatially distributed points. In order to overcome these difficulties, the velocity meter must be relatively inexpensive and easily reproducible. Conventional instruments do not meet these criteria. However, recent work has developed velocity meters based on different measurement principles with the aim of reducing costs. The current meters developed by Marchant et al. (2014) and Johansen (2014) are based on the principle of drag force, and they meet the criteria of reliability and low cost.

In urban drainage channels, high flow velocities are often observed as rapid temporal variation in discharge during rainfall events. These events generally occur in regions of steep slopes (common in urban rivers, including meandering ones) and in channels flowing between smooth banks. Under these conditions, a supercritical flow with considerable turbulence is generated, which causes temporal fluctuations in velocity direction and magnitude. In order to characterize these flows, the velocity measurements must have a high sampling frequency. Thus, turbulent fluctuations and other uncertainties in input variables are evaluated and propagated to the output mean velocities. High precision devices would not be necessary in such cases because there are significant uncertainties inherent to turbulent flow.

To solve these issues, in this work, we propose a low-cost velocity meter that is easily reproducible and that yields an accurate response to turbulent flow. The further development of instruments with such characteristics could be beneficial for cost-sensitive projects, such as measurements in urban drainage channels and other environmental surveillance, for which a reasonable quality of the output estimates is sufficient.

The method used in differential head meters was chosen because of their simplicity. A prototype based on the Pitot principle was built, and the velocities estimated and the uncertainties were analyzed statistically. This instrument's performance on an experimental channel was compared to that of an acoustic current meter. This work presents the performance evaluation and discusses the potential of similar velocity meters for use in open-channel hydrometric applications.

\section{Differential head meters}

In 1732, French engineer Henri Pitot (1695-1771) invented the instrument that bears his name. In its original form, the Pitot tube consisted of a simple pipe that was bent at $90^{\circ}$, the open end of which faced upstream in alignment with the flow direction. Although the invention was credited to Pitot, it was Henry Darcy (1803-1858) who published a study that revolutionized the instrument and brought it into large-scale use (BROWN, 2003).

The simplified theory of the operation of a Pitot tube is a derivation of the Bernoulli equation applied to two points of a streamline with the following constraints: flow in incompressible fluid, in steady state, and without friction. When these points are indicated by 1 and 2, the Bernoulli equation is as follows:

$$
\frac{P_{1}}{\gamma}+\frac{U_{1}^{2}}{2 g}+z_{1}=\frac{P_{2}}{\gamma}+\frac{U_{2}^{2}}{2 g}+z_{2}
$$

where

- $\quad P_{1}$ and $P_{2}$ - static pressure at points 1 and 2;

- $U_{1}$ and $U_{2}-$ local fluid velocity at points 1 and 2;

- $z_{1}$ and $z_{2}$ - elevation head of points 1 and 2;

- $\gamma$ - specific weight of fluid;

- $g-$ acceleration of gravity.

When a Pitot tube is inserted into the flow, the fluid is decelerated to zero velocity at the nose of the probe (FOX; McDONALD, 2001). By conveying this nose as point 2 so that $U_{2}=0$ and point 1 as a point at the same elevation but at a certain distance denoted by $\infty$ where it is not influenced by the Pitot tube, Equation 1 results in Equation 2. The terms $P_{\infty} / \gamma$ and $P_{2} / \gamma$ correspond respectively 
to the static head and the total head (also called the stagnation head). The quantity represented by $U_{\infty}{ }^{2} / 2 g$ is called the velocity head or the dynamic head.

$$
\frac{P_{\infty}}{\gamma}+\frac{U_{\infty}^{2}}{2 g}=\frac{P_{2}}{\gamma}
$$

When the static and stagnation heads have been measured, which is done by means of appropriate probes, the point velocity $U_{\infty}$ is estimated by Equation 3 .

$$
U_{\infty}=\sqrt{\frac{2 g\left(P_{2}-P_{\infty}\right)}{\gamma}}
$$

In closed conduits, it is usual to combine two probes in a device known as a Prandtl tube or a Pitot-static tube. While one probe performs the main function of a Pitot tube by decelerating the fluid and measuring the impact (stagnation) pressure $\left(P_{2}\right)$, the other probe measures the static pressure $\left(P_{\infty}\right)$. The latter is sensed at piezometer holes placed on the side of the tube perpendicular to the flow direction. In Equation 3, the difference between the two measures relates to velocity $\left(U_{\infty}\right)$. Variations of this velocity meter include the Pitot-Cole, Kiel probe, and Stanton and Preston tubes (FINNEMORE; FRANZINI, 2002).

In open-channel flows that are predominantly unidirectional, it is possible to estimate the velocity with only the stagnation (total head) probe. In these cases, if the streamlines are not curved, the static head corresponds to the elevation of the free surface $(h s)$, and it can be measured directly with respect to the bottom of the channel. The total head then corresponds to the water level $(h p)$ in a manometer coupled to the nose of the Pitot tube where the stagnation point occurs. The single probe of this design must not disturb the flow and its axis must be aligned parallel to the streamlines. This arrangement was idealized in (Figure 1). The difference between total and static heads gives the velocity head $(\Delta h)$ :

$$
\Delta h=h p-h s
$$

Equation 5 gives the general expression of the Pitot tube:

$$
U=\mu \sqrt{2 g \Delta h}
$$

where $U$ is the point velocity, $\mu$ is the dimensionless calibration coefficient, and $\Delta h$ is the observed velocity head.

According to Finnemore and Franzini (2002), the calibration coefficient $\mu$ is necessary because the directional velocity fluctuations caused by turbulence affect the Pitot tube readings. The authors further stated that most Pitot devices provide reasonably accurate results when the misalignment between the stagnation probe axis and the approaching flow direction is less than $\pm 15^{\circ}$. The coefficient $\mu$ also depends on the nose geometry and the diameter of its opening, which should not be large relative to the velocity profile steepness (REPLOGUE; WAHLIN, 2000). In liquid flows, these effects are minimized, and $\mu$ typically approaches unity. As Darcy observed, if the diameter of the opening is too large, it can cause vibrations in the total head readings. If it is too small, it can cause air to be trapped (BROWN, 2003).

Pitot tubes are usually not used in open-channel flow measurements. When this is the case, generally, they are employed only to measure velocities that are very close to a boundary or

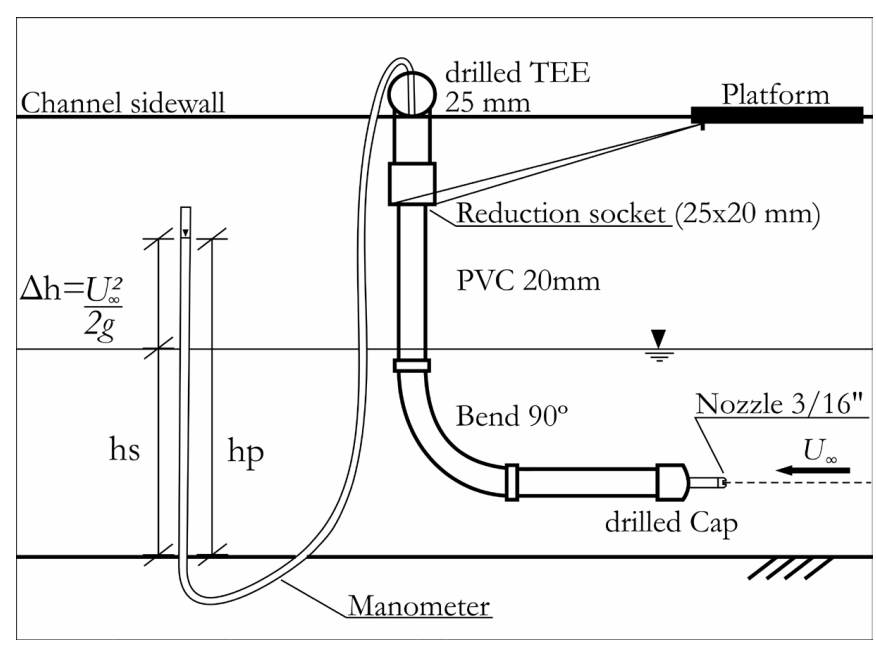

Figure 1. Schematic representation of the prototype device.

when an accurate velocity profile over a section of the channel or over a hydraulic structure is desired (ASKARI et al., 2015; DURGA RAO; PILLAI, 2008). Among the main disadvantages of the Pitot tube is the small size of the opening, which can be plugged by sediments or other suspended materials, thus affecting the results (WMO, 2010b). Nevertheless, Nikora and Smart (1997) and Magirl et al. (2009) demonstrated the use of a Pitot device to quantify velocities of up to $6.5 \mathrm{~m} / \mathrm{s}$ in rivers. In this case, the instrument employed, which was developed by Smart (1991), was suited for field deployment. According to the authors, the instrument, the name of which was abbreviated as P.O.E.M, made it possible to measure flow velocities up to $9.0 \mathrm{~m} / \mathrm{s}$.

Another notable velocity head meter was described by Fonstad et al. (2005). Inexpensive and simply constructed, this instrument consists of a transparent acrylic board to which measuring rules are attached. During the operation, the board is maintained perpendicular to the direction of the approaching flow. Similar to the principle by which the Pitot tube operates, the fluid dams on the upstream face, so that the difference between the water level in the upstream and downstream faces is a rough estimate of the velocity head for an average over the entire water column. This instrument is called the Transparent Velocity Head Rod (TVRH). Velocities between 0.4 and $1.4 \mathrm{~m} / \mathrm{s}$ were measured with the TVRH and showed a reasonable correlation after calibration with a Price AA current meter.

\section{MATERIAL AND METHODS}

The Pitot tube was tested in a laboratory channel. The prototype is a simple instrument that can be reproduced with widely accessible components. It can be made in a very small size in order to create minimal flow disturbance, and it allows velocity measurements in sections as little as $2.0 \mathrm{~cm}$ deep.

\section{Construction of the prototype}

The Pitot tube was built in its simplest configuration with only a total head probe. The instrument has three main elements: a tip where the nose is placed; a PVC frame; and a 
An alternative method for measuring velocities in open-channel flows: perfomance evaluation of a Pitot tube compared to an acoustic meter

U-tube manometer for reading $h p$, as shown in Figure 1. The use of a pressure gauge, such as a Bourdon manometer, is limited to the sensitivity requested at low velocities. In open channels, the velocity head differentials $(\Delta h)$ may be smaller than the gauge's resolution. For measurements taken in subcritical flow with low velocities, differentials of the order of $1 \mathrm{~mm}$ were generated; such readings are difficult or impossible with ordinary pressure gauges.

For the nose of the Pitot tube, the following materials were tested: a pissette nozzle, a boat speedometer (Pitot tube type), and the three nozzles of a DH-48 sediment sampler with diameters of $1 / 4 ", 1 / 8$ ", and $3 / 16 "$. As expected, different measurement responses were obtained by each of the materials tested according to the diameter and geometry of the nozzle. The pissette nozzle and the boat speedometer were discarded because of the entrapment and/or entrance of air bubbles or operational difficulties. Among the three nozzles of the sediment sampler, the one with the smallest opening (3/16") was chosen because it produced the smallest amplitude oscillations at the water level $h p$ registered in the manometer. The 3/16" nozzle was plugged into the silicone hose, and both were placed inside the PVC frame, which had a drilled cap on its tip.

The frame consisted of PVC pipes and fittings. It acted as the probe support, and it functioned to house the nozzle and the silicone hose, in addition to keeping the Pitot tube suspended in the flow direction while leaning against the channel sidewall such that the tip of the nose was maintained pointing upstream. A distance was created between the nose and the vertical support to prevent possible flow disturbances caused by the latter from reaching the sensing hole and affecting the quality of the measurements.

The transparent silicone hose acted as a U-tube manometer. One end was connected to the stagnation pressure-sensing hole (3/16" nozzle), and the other end was open to the atmospheric pressure. The hose was attached to the outer side of the channel sidewall, which is transparent, in the form of a siphon. This configuration allowed readings to be taken on the sidewall where a measuring ruler with a precision of $1.0 \mathrm{~mm}$ was fixed with its zero level at the bottom of the channel. Hence, the height of the meniscus on the manometer $(h p)$ and the elevation of the free surface $(h s)$ could both be read on the same ruler, thus avoiding the errors that could occur if the readings were performed individually and with more than one reference.

\section{Measurement methodology}

The tests were performed in a glass-lined channel with rectangular section that was fed in closed circuit by a motor and pump assembly. The Pitot tube measurements were compared to those taken by an acoustic Doppler velocimeter (ADV) developed by SonTek/YSI with the trade name Flowtracker. Both instruments were submitted to different velocities in the channel. The system was kept in steady state flow during each measurement. In order to achieve the steady state without changing the channel slope, the flow conditions of flow rate and water depth (at the measurement sections) varied in each velocity measured. The flow rate was controlled by a valve located at the discharge pipe, and the flow depth was controlled by sluice gates that were placed upstream and downstream of the channel. Measurements were performed in uniform flow with subcritical or supercritical conditions. The uniform flow was verified because water depths remained constant in the measurement sections and between them.

It is worth highlighting that the measurements were not performed with the instruments placed at the same cross section. This configuration was tested, and the result showed a sudden contraction in the flow; consequently, interferences were verified in the velocity field. These occurred because the channel width of $17.5 \mathrm{~cm}$ was small in relation to the dimensions of the instruments. Therefore, the experimental system shown in Figures 2 and 3 was designed. The arrangement allowed the meters to perform estimates for a point velocity located at the same depth and at the same distance from the channel sidewalls even though the instruments were placed at different cross sections. Moreover, it was assumed that the velocities measured with both instruments were equivalent because the measurement points were placed along the same trajectory.

The arrangement illustrated in Figure 2 shows the transverse spacing between the meters in the y direction. It was adopted so that the sampling volume of the ADV coincided with the measurement point of the Pitot tube at its nose. Following the manufacturer's instructions, this sampling volume was located $10 \mathrm{~cm}$ away from the acoustic transmitter (SONTEK; YSI INCORPORATED, 2007). As shown in Figure 3, a space between the instruments along the $\mathrm{x}$ direction was also established. The purpose of this spacing was to ensure the development of the flow and prevent eventual disturbances created by the Pitot probe from reaching the ADV measurement point.

In order to validate the methodology described so far, one measurement was performed with the ADV and the Pitot tube positioned in the same cross section at different times. The results are presented in the performance comparison.

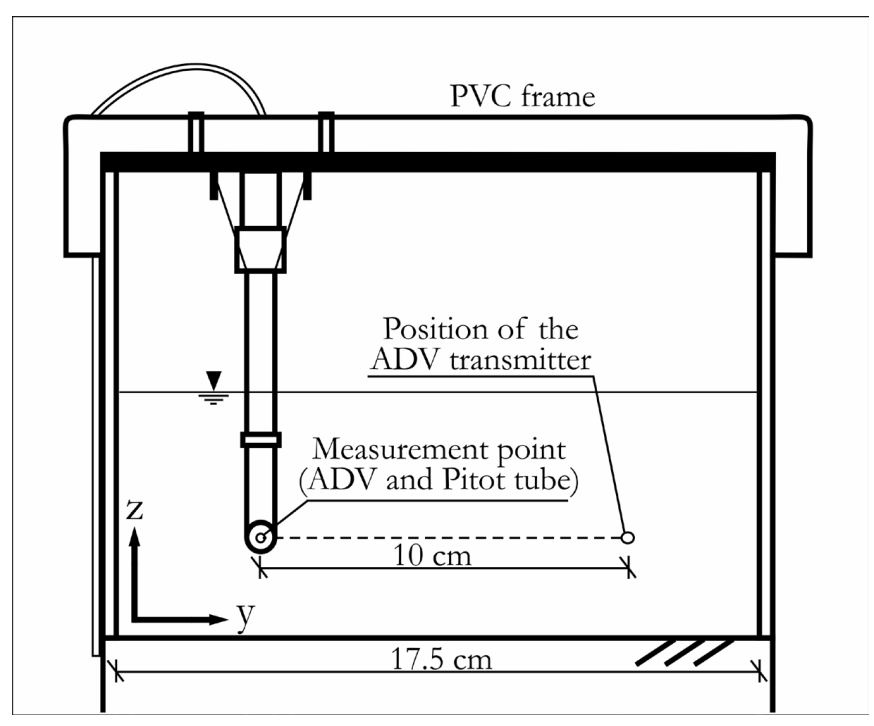

Figure 2. Cross sectional view of the experimental system. For the positioning illustrated the measurement point of the Pitot tube (at its nose) coincides with the ADV sampling volume both in $\mathrm{y}$ and $\mathrm{z}$ directions. 


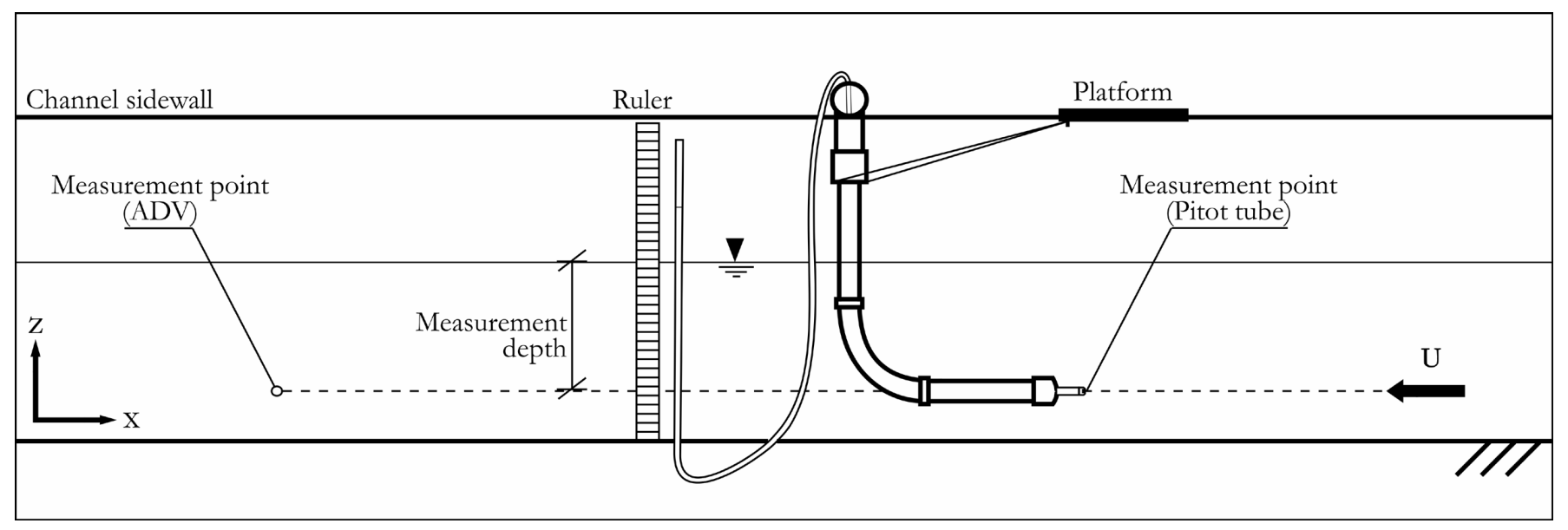

Figure 3. Longitudinal view of the experimental system.

Because of operational difficulties, the readings were not taken simultaneously on both meters. When a specific condition of flow rate and water depth was imposed in the channel, the corresponding velocity was measured with the ADV, and then the total head readings were taken with the Pitot tube. The results reported at the ADV served as references to track the velocities that were being generated for the successive measurements. This procedure was consistent because the flow rate could be controlled by the valve, and it was kept constant so that the obtained flow was steady during each measurement.

The velocity displayed on the ADV screen, denoted by $U_{a d v}$, is the mean value of a series of instantaneous readings. The measurement method was designed so that the Pitot tube could also perform instantaneous readings. Thus, the velocity obtained with the latter, denoted by $U_{\text {pitot }}$, also corresponded to the mean of a series. Each velocity generated in the channel corresponded to a different value of the measurand, which could only be estimated using the ADV and Pitot tube series. The means and the instantaneous velocities observed in each method were compared. This allowed for evaluating the uncertainties and the reliability of the prototype in relation to the already consolidated equipment.

\section{ADV velocity measurements}

The following parameters were computed with the ADV for each measurement: mean velocity $\left(U_{a d v}\right)$, instantaneous values $\left(U_{a d v_{i}}\right)$, number of outliers, acoustic signal quality, and the standard deviation of the sample. Using these data, the coefficients of variation $\left(C V_{a d v}\right)$ were calculated.

As previously stated, the velocity reported directly on the ADV corresponds to the arithmetic mean of a series of one-second velocities. The total duration of this series is defined by the user. In this experiment, it was established in 40 seconds. The one-second velocities were the averages of 10 acoustic pulses. Therefore, the ADV measured at the frequency of $10 \mathrm{~Hz}$.

The quality of velocity estimates, with respect to the acoustic signal, was evaluated by the signal-to-noise ratio (SNR) and the boundary quality control flag. Both these parameters were provided in the equipment. SNR is a measure of the strength of the reflected acoustic signal relative to the ambient noise level (REHMEL, 2007). It should be higher than $10 \mathrm{~dB}$ to obtain consistent estimates (SONTEK; YSI INCORPORATED, 2007). ADV detects possible interferences in the acoustic signal caused by the bottom and sidewalls of the channel, and it performs a boundary adjustment if they are present, which is often the case when the flow depth is small. In the data sampled, SNR was around $50 \mathrm{~dB}$ in the measurements (minimum verified was $35.3 \mathrm{~dB}$ ). No boundary adjustments were necessary because the quality control flag indicated that the interferences would have no or a minimal effect on the velocity estimates.

A filter in the ADV algorithm removes from the sample values that are greater or less than 1.5 times the interval between quartiles with respect to the median, which are considered outliers. The filtered mean value is displayed on the screen while the one-second velocities are recorded by the equipment. These values were compared with the instantaneous results obtained in the Pitot tube readings.

The 2-D probes of the ADV measured the velocity components in the longitudinal $\left(V_{x}\right)$ and transverse $\left(V_{y}\right)$ directions, with respect to the axes of the equipment. This allowed for computing the angle between the mean direction of flow and the direction that was perpendicular to the cross section. During the operation, the velocities were taken in such a way that the theoretical axes of the ADV coincided with the $\mathrm{x}$ and $\mathrm{y}$ directions illustrated in Figures 2 and 3. Even so, small-magnitude velocities were verified in the $y$ direction due to deviation angles smaller than $7^{\circ}$, which produced an error of less than $1 \%$ in the estimates. These deviations may have occurred because of the misalignment of the ADV during operation or the actual variations in the flow instantaneous direction caused by the turbulence. Because the effect of these variations was slight, and the flow was predominantly unidirectional, $V_{y}$ was disregarded in subsequent procedures. Therefore,

$U_{a d v}=V_{x}$ 
An alternative method for measuring velocities in open-channel flows: perfomance evaluation of a Pitot tube compared to an acoustic meter

\section{Pitot tube velocity measurements}

To stabilize the alignment of the axis of the Pitot tube with the flow direction and maintain the vertical deviations below $\pm 10^{\circ}$, the instrument was supported by a mobile cable-stayed platform that was placed on top of the channel sidewalls, as illustrated in Figure 3. Deviations in the y direction were possible because the angle of attack depended on the instantaneous direction of the flow. However, it was found that this angle did not exceed a tolerance limit of $\pm 10^{\circ}$.

For each flow rate and depth, after verifying the reference velocity $\left(U_{a d v}\right)$, the following readings were taken on the measuring ruler:

- $h p(\mathrm{~cm})$ - height of meniscus on the manometer, which corresponds to total head (stagnation);

- $h s(\mathrm{~cm})$ - flow depth at the measurement point, which corresponds to the static head.

The methodology described in this section followed the procedures and terminology of the Guide for the Expression of Uncertainty in Measurements (GUM) JCGM, 2008). These procedures are based on the propagation of uncertainties through an approximation of the measurement model using the Taylor series expansion. For the Pitot tube results, the GUM framework was used to analyze the sensitivity of the measured velocities relative to the uncertainties contained in the input variables, $h p$ and $h s$. The quality of the final estimates was assessed according to their expanded uncertainties.

The GUM classifies uncertainties into two groups: type A, which are evaluated by statistical methods, and type $\mathrm{B}$, which are evaluated by other means. In the latter, the analysis is based on information obtained from external sources or through probabilistic distributions adopted for the input variables according to the specificities of the experimental procedures. Muste et al. (2012) used the GUM in a hydrometric application.

Random errors in the readings of $h s$ and $h p$ resulting from the $\pm 1 \mathrm{~mm}$ resolution of the ruler were evaluated as type $B$ uncertainties. Water level oscillations affecting $h s$ were also evaluated using this method.

For each velocity measured, instantaneous fluctuations in flow depth in the order of a few millimeters were observed. The best estimate of $h s$ was considered the average of the readings of maximum $\left(h s_{+}\right)$and minimum depths $\left(h s_{-}\right)$expanded by $1 \mathrm{~mm}$ to contain the resolution errors. Therefore, $h s$ corresponds to the mean of a rectangular distribution with upper and lower limits in $h s_{+}$and $h s_{-}$, respectively. The uncertainty component for this variable is represented by the variance of the adopted uniform distribution, denoted by $u^{2}(h s)\left(\mathrm{cm}^{2}\right)$ and calculated according to Equation 7.

$u^{2}(h s)=\frac{\left(h s_{+}-h s_{-}\right)^{2}}{12}$

In contrast, the total head readings $(h p)$ showed fluctuations with a greater range than in the $h s$ readings. In some measurements, the meniscus oscillated between positions that differed by several centimeters. The amplitudes of these oscillations were larger in velocities over $0.8 \mathrm{~m} / \mathrm{s}$, in which the flow was supercritical. To record $h p$ instantaneously and evaluate the effects of oscillation, videos 40 seconds in duration were recorded to indicate the position of the meniscus and the corresponding height of the ruler. This duration was adopted in order to obtain a time series that was the same size as the ADV. Readings of the instantaneous total heads, denoted by $h p_{i}$, were taken for each second of the recording, which corresponded to a sampling frequency of $1 \mathrm{~Hz}$.

In each measurement, the best estimate of $h p$ corresponded to the average of the $40 h p_{i}$ readings. Type A uncertainties in this variable were estimated using the experimental variance of the mean $u_{A}^{2}(h p)\left(\mathrm{cm}^{2}\right)$ and then calculated with the observed standard deviation of each sample $\left(s_{h p}\right)$ according to Equation 8. In this paper, type B uncertainties were also evaluated in order to represent the random errors introduced by the limited resolution of the ruler. This was done through another rectangular distribution lying between $\pm 1 \mathrm{~mm}$ with its variance, which was denoted by $u_{B}^{2}(h p)\left(\mathrm{cm}^{2}\right)$, calculated according to Equation 9.

$$
\begin{aligned}
& u_{A}^{2}(h p)=\frac{s_{h p}^{2}}{40} \\
& u_{B}^{2}(h p)=\frac{(0.1)^{2}}{3}
\end{aligned}
$$

These type A and type B uncertainties were summed, resulting in $u^{2}(h p)$, which represents the uncertainty component of total head readings:

$$
u^{2}(h p)=u_{A}^{2}(h p)+u_{B}^{2}(h p)
$$

The best estimate of the flow velocity using the Pitot tube $\left(U_{\text {pitot }}\right)$ was calculated with the averages $h p$ and $h s$ inserted in Equation 11. The result of this expression is given in $\mathrm{m} / \mathrm{s}$, and it is equivalent to Equation 5, assuming that the calibration coefficient is equal to unity $(\mu=1)$ and that the $h p$ and $h s$ measures were taken in centimeters.

$U_{\text {pitot }}=\sqrt{\frac{g(h p-h s)}{50}}$

The combined standard uncertainty of the Pitot tube estimates, denoted by $u_{c}^{2}\left(U_{\text {pitot }}\right)(\mathrm{m} / \mathrm{s})^{2}$, was obtained according to Equation 12.

$$
u_{c}^{2}\left(U_{\text {pitot }}\right)=\left(\frac{\partial U}{\partial h s}\right)^{2} u^{2}(h s)+\left(\frac{\partial U}{\partial h p}\right)^{2} u^{2}(h p)
$$

Equation 12 approximates the functional relationship of $U_{\text {pitot }}(h p, h s)$ using a first-order Taylor series expansion. The partial derivatives in this equation correspond to the sensitivity coefficients, which quantify the influence of variations in the input variables over the output velocity estimates. The higher order terms in the Taylor series were disregarded because it was found that their magnitude was small in comparison to the first-order sensitivity coefficients. Therefore, there was no significant influence on the propagation of uncertainties.

Expanded uncertainty was finally obtained by applying the coverage factor $k=2$ relative to a confidence interval of approximately $95 \%$. This value is recommended for use in most practical applications (JCGM, 2008). The Pitot tube estimates were 
reported as the mean velocity and its expanded uncertainties as $U_{\text {pitot }} \pm k u_{c}\left(U_{\text {pitot }}\right)$. This information was better represented when the uncertainties were expressed in the relative terms $(\Delta U / U)$ which were computed by Equation 13 .

$$
\frac{\Delta U}{U}=\frac{k u_{c}(U)}{U_{\text {pitot }}}
$$

In order to assess the dynamic response of the Pitot tube, the instantaneous velocity head differentials $\left(\Delta h_{i}\right)$ and the instantaneous velocities $\left(U_{\text {pitot }_{i}}\right)$ of each measurement were computed according to Equations 14 and 15. In the latter, the instantaneous values of the total head readings $\left(h p_{i}\right)$ were used.

$$
\Delta h_{i}=h p_{i}-h s
$$

$$
U_{\text {pitot }_{i}}=\sqrt{\frac{g\left(h p_{i}-h s\right)}{50}}
$$

The standard deviation $\left(s_{\text {pitot }}\right)$ of each $U_{\text {pitot }}$ sample was computed. Based on the standard deviation and the mean velocity $\left(U_{\text {pitot }}\right)$, the coefficient of variation $\left(\mathrm{CV}_{\text {pitot }}\right)$ was obtained. The distributions of instantaneous velocities were analyzed statistically by normality tests. The time-averaged velocities that were measured with both instruments, $U_{\text {pitot }}$ and $U_{a d v}$, were correlated in order to evaluate the performance of the prototype. These procedures are shown by the flow chart in Figure 4.

\section{RESULTS AND DISCUSSION}

\section{Uncertainty analysis of the Pitot tube}

A total of 50 measurements were performed, which were divided into two groups: 21 series of instantaneous readings of velocities from $0.20-0.60 \mathrm{~m} / \mathrm{s}$ obtained in subcritical flow $(F r<0.53)$; and 29 series of instantaneous readings of velocities from $0.85-2.00 \mathrm{~m} / \mathrm{s}$ obtained in supercritical flow $(F r>1.3)$. These results are presented in Tables 1 and 2 . Froude numbers $(F r)$ were calculated based on the time-averaged ADV velocities.

Minimum velocity $U_{\text {pitot }}$ was $0.21 \pm 0.10 \mathrm{~m} / \mathrm{s}$ in which a time-averaged velocity head $(\Delta h)$ of $0.2 \mathrm{~cm}$ was observed, according to which the discrimination threshold of the Pitot tube method was defined. This result was obtained in subcritical flow with the minimum oscillation of the free surface. For lower velocities verified by the ADV, which had a higher measuring resolution, the averaged water level $(h s)$ overlapped the height of the meniscus (hp). The maximum Pitot tube velocity was $1.92 \pm 0.03 \mathrm{~m} / \mathrm{s}$ with a maximum instantaneous recording of $2.09 \mathrm{~m} / \mathrm{s}$ obtained in a supercritical flow. Other results varied from $0.20 \mathrm{~m} / \mathrm{s}$ to the channel maximum of approximately $2.00 \mathrm{~m} / \mathrm{s}$ with a discontinuity between 0.60 and $0.80 \mathrm{~m} / \mathrm{s}$, which was explained by the transition zone between the subcritical and supercritical flows.

The uncertainty propagation resulted in relative uncertainties $(\Delta U / U)$ ranging from $51 \%$ to $1 \%$. This contrast was caused by the sensitivity coefficients and the functional relationship of the Pitot tube. The latter is a square root function, which implies that the coefficients obtained as partial derivatives of Equation 11 are decreasing functions of the measurand (local velocity). For this reason, the output velocities were less influenced by the

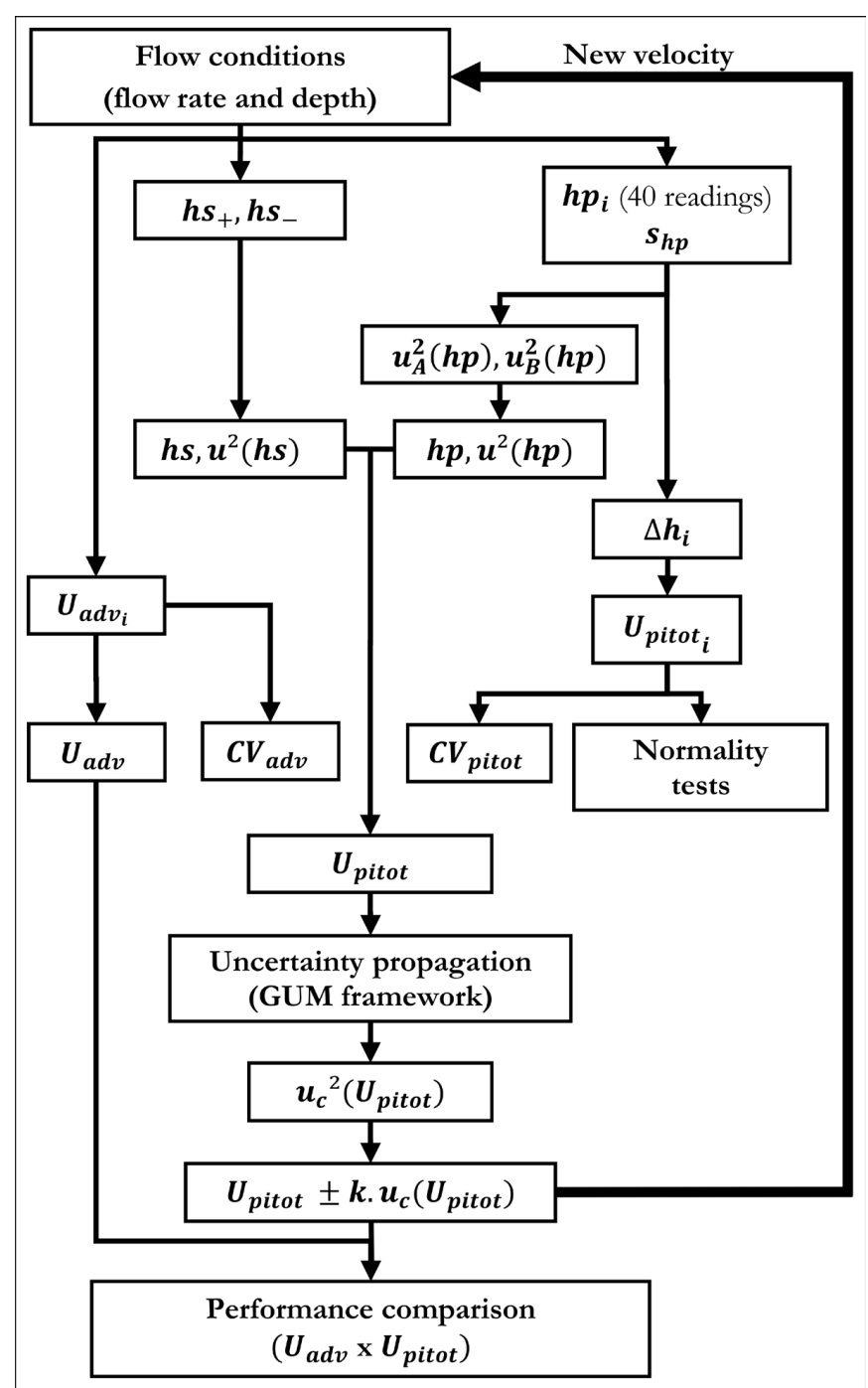

Figure 4. Flow chart showing the procedures for determination of velocities and expanded uncertainties.

uncertainties in the input variables as the local velocity increased. For example, the sensitivity coefficients calculated for $0.2 \mathrm{~m} / \mathrm{s}$ were 10 times higher than were those calculated for $2.0 \mathrm{~m} / \mathrm{s}$. This result demonstrates that the Pitot tube is appropriate for measuring high velocities. Theoretically, there are no limitations on the accurate quantification of a maximum flow velocity, as long as the stagnation pressure is maintained at the nose of the instrument. The higher the velocity, the lower the expanded uncertainty resulting from limited instrument resolution, insufficient sample size, or insufficient sampling frequency. In accordance with these observations, in flow velocities over $1.2 \mathrm{~m} / \mathrm{s}$, the uncertainty was below $3 \%$ in all cases.

The readings measured by the ruler contained random errors because of its $1 \mathrm{~mm}$ resolution. In terms of pressure head, this means $10^{-3} \mathrm{mH} 2 \mathrm{O}$. A sensitivity analysis of only the uncertainties propagated from this source was performed following the GUM framework. For velocities of $0.21,0.57$, and $1.00 \mathrm{~m} / \mathrm{s}, 1 \mathrm{~mm}$ reading errors in $h s$ and $h p$ resulted in uncertainties of 35\%, 5\%, and $2 \%$, respectively. These values demonstrate that the measuring 
Table 1. Measurement results of subcritical flow.

\begin{tabular}{|c|c|c|c|c|c|c|}
\hline $\begin{array}{c}U_{a d v} \\
\mathrm{~m} / \mathrm{s}\end{array}$ & $\begin{array}{c}C V_{a d v} \\
\%\end{array}$ & & $\begin{array}{l}U_{\text {pitot }} \\
\mathrm{m} / \mathrm{s}\end{array}$ & & $\begin{array}{c}C V_{\text {pitot }} \\
\%\end{array}$ & $\begin{array}{c}\Delta U / U \\
\%\end{array}$ \\
\hline 0.215 & 8.8 & 0.21 & \pm & 0.10 & 0.0 & 45 \\
\hline 0.240 & 7.9 & 0.24 & \pm & 0.10 & 6.2 & 45 \\
\hline 0.251 & 10.1 & 0.27 & \pm & 0.07 & 0.0 & 28 \\
\hline 0.277 & 9.1 & 0.27 & \pm & 0.09 & 14.0 & 35 \\
\hline 0.280 & 9.0 & 0.29 & \pm & 0.09 & 16.8 & 30 \\
\hline 0.283 & 11.2 & 0.31 & \pm & 0.13 & 12.4 & 43 \\
\hline 0.340 & 9.3 & 0.30 & \pm & 0.17 & 12.6 & 51 \\
\hline 0.345 & 7.3 & 0.35 & \pm & 0.08 & 8.8 & 25 \\
\hline 0.361 & 8.8 & 0.41 & \pm & 0.05 & 5.9 & 12 \\
\hline 0.373 & 10.2 & 0.39 & \pm & 0.06 & 7.1 & 17 \\
\hline 0.374 & 5.1 & 0.40 & \pm & 0.11 & 7.3 & 29 \\
\hline 0.375 & 8.4 & 0.43 & \pm & 0.09 & 5.7 & 22 \\
\hline 0.408 & 7.8 & 0.39 & \pm & 0.09 & 11.1 & 24 \\
\hline 0.423 & 7.5 & 0.51 & \pm & 0.09 & 5.0 & 18 \\
\hline 0.441 & 10.0 & 0.46 & \pm & 0.09 & 6.7 & 20 \\
\hline 0.442 & 8.6 & 0.36 & \pm & 0.11 & 12.0 & 27 \\
\hline 0.451 & 14.0 & 0.50 & \pm & 0.09 & 6.3 & 17 \\
\hline 0.471 & 10.7 & 0.54 & \pm & 0.07 & 6.2 & 13 \\
\hline 0.498 & 11.4 & 0.57 & \pm & 0.06 & 8.0 & 11 \\
\hline 0.505 & 8.8 & 0.47 & \pm & 0.20 & 8.0 & 41 \\
\hline 0.510 & 13.6 & 0.57 & \pm & 0.10 & 6.0 & 18 \\
\hline
\end{tabular}

Uadv* / Upitot* - Mean of instantaneous velocities; CVadv** / CVpitot** _ Coefficient of variation of instantaneous velocities; Delta U/U***-Relative expanded uncertainty

Table 2. Measurement results of supercritical flow.

\begin{tabular}{|c|c|c|c|c|c|c|}
\hline $\begin{array}{l}U_{a d v} \\
\mathrm{~m} / \mathrm{s}\end{array}$ & $\begin{array}{c}C V_{\text {adV }} \\
\%\end{array}$ & & $\begin{array}{l}U_{\text {pitot }} \\
\mathrm{m} / \mathrm{s}\end{array}$ & & $\begin{array}{c}C V_{\text {pitot }} \\
\%\end{array}$ & $\begin{array}{c}\Delta U / U \\
\%\end{array}$ \\
\hline 0.871 & 10.2 & 0.95 & \pm & 0.03 & 6.0 & 3 \\
\hline 0.884 & 12.9 & 0.97 & \pm & 0.03 & 7.0 & 3 \\
\hline 0.907 & 6.3 & 0.92 & \pm & 0.04 & 5.0 & 5 \\
\hline 0.980 & 5.8 & 0.97 & \pm & 0.03 & 5.3 & 3 \\
\hline 0.990 & 5.7 & 0.99 & \pm & 0.04 & 3.3 & 4 \\
\hline 0.994 & 7.6 & 1.03 & \pm & 0.03 & 5.8 & 3 \\
\hline 1.008 & 5.6 & 1.02 & \pm & 0.02 & 4.1 & 2 \\
\hline 1.014 & 5.6 & 1.03 & \pm & 0.03 & 4.6 & 3 \\
\hline 1.017 & 5.0 & 0.98 & \pm & 0.03 & 5.4 & 3 \\
\hline 1.027 & 6.2 & 1.00 & \pm & 0.05 & 4.3 & 5 \\
\hline 1.028 & 7.4 & 1.00 & \pm & 0.04 & 4.6 & 4 \\
\hline 1.202 & 4.7 & 1.15 & \pm & 0.04 & 4.7 & 3 \\
\hline 1.203 & 6.8 & 1.20 & \pm & 0.02 & 3.8 & 2 \\
\hline 1.285 & 4.4 & 1.10 & \pm & 0.02 & 2.3 & 2 \\
\hline 1.331 & 6.7 & 1.32 & \pm & 0.02 & 3.8 & 2 \\
\hline 1.340 & 4.7 & 1.30 & \pm & 0.02 & 3.0 & 2 \\
\hline 1.367 & 3.2 & 1.23 & \pm & 0.03 & 4.0 & 2 \\
\hline 1.448 & 3.9 & 1.34 & \pm & 0.03 & 2.8 & 2 \\
\hline 1.609 & 3.1 & 1.57 & \pm & 0.02 & 2.0 & 1 \\
\hline 1.673 & 2.6 & 1.63 & \pm & 0.02 & 2.4 & 1 \\
\hline 1.675 & 4.2 & 1.57 & \pm & 0.03 & 3.1 & 2 \\
\hline 1.707 & 3.7 & 1.66 & \pm & 0.02 & 2.1 & 1 \\
\hline 1.750 & 3.3 & 1.69 & \pm & 0.02 & 3.0 & 1 \\
\hline 1.759 & 4.0 & 1.77 & \pm & 0.02 & 2.3 & 1 \\
\hline 1.805 & 4.6 & 1.79 & \pm & 0.03 & 4.0 & 2 \\
\hline 1.841 & 3.4 & 1.74 & \pm & 0.03 & 4.1 & 2 \\
\hline 1.887 & 3.4 & 1.82 & \pm & 0.03 & 3.5 & 2 \\
\hline 1.973 & 4.8 & 1.90 & \pm & 0.02 & 3.6 & 1 \\
\hline 1.977 & 3.5 & 1.92 & \pm & 0.03 & 4.0 & 1 \\
\hline
\end{tabular}

Uadv* / Upitot* - Mean of instantaneous velocities; CVadv** / CVpitot**-Coefficient of variation of instantaneous velocities; Delta U/U*** - Relative expanded uncertainty resolution is significant for velocity estimates below $0.60 \mathrm{~m} / \mathrm{s}$. However, the adoption of sensors with an improved resolution, such as of $10^{-4} \mathrm{mH} 2 \mathrm{O}$, is unnecessary in velocity measurements over $1.0 \mathrm{~m} / \mathrm{s}$ because such enhancement would have a minimal effect on the expanded uncertainties $(\leq 2 \%)$. Furthermore, at higher velocities, the uncertainties arising from this source may be overcome by uncertainties caused by the fluctuations in static (flow depth) and total head readings.

Concerning the flow depth readings $(h s)$, ranges up to a maximum of $16 \mathrm{~mm}$ were recorded in the samples. These variations occurred because of small free-surface disturbances caused by internal turbulence and air currents. Combined with the instrument resolution uncertainty, the variations in $h s$ caused a minimal quantity of uncertainty in the estimates, particularly in low velocities of subcritical flow because of the magnitude of sensitivity coefficients. In addition, the velocities in subcritical flow are usually measured in larger depths and therefore are more susceptible to oscillations in the readings of $h s$. In the testing channel, disturbances on the free surface were present but at a much-reduced intensity compared to the field flows. One way of minimizing the uncertainties from this source is to perform $h s$ readings at a higher sampling frequency, thus allowing the variations to be evaluated as type A uncertainties, which then have smaller experimental variances.

The Pitot tube's response to increasing water velocity was characterized by unsteadiness and increasingly larger oscillations of instantaneous total head readings $\left(h p_{i}\right)$. These oscillations are better visualized in terms of the instantaneous velocity head readings $\left(\Delta h_{i}\right)$ shown in Figure 5. Type A uncertainties, as random variations of each $\Delta h$ sample, are presented in this figure. The solid line represents the theoretical curve of Equation 5 in terms of the velocity head fitted to the experimental data. Considering the optimal correction factor of 0.94 , the recorded values of

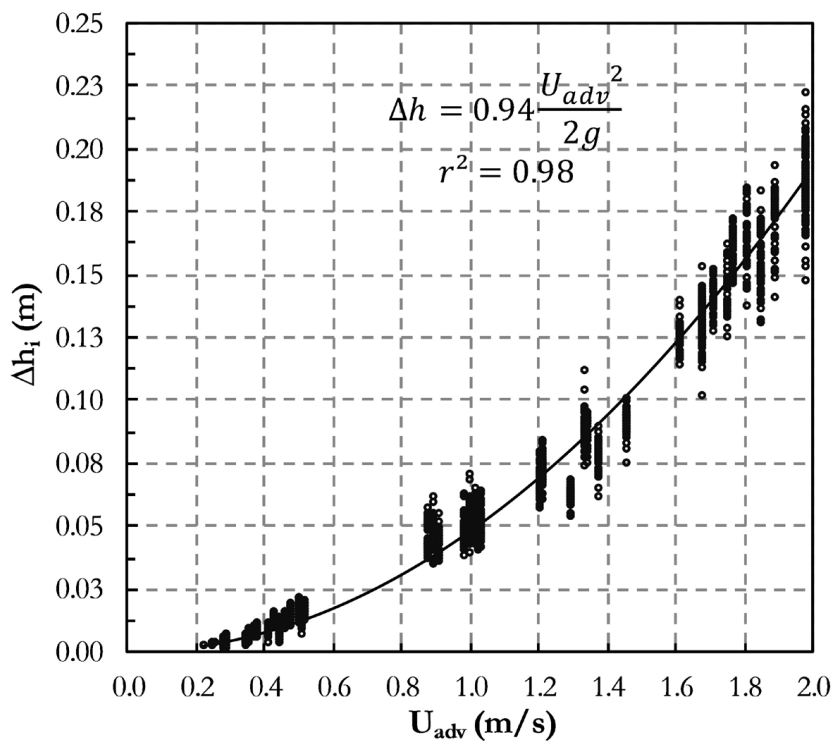

Figure 5. Samples of instantaneous velocity head $\left(\Delta \boldsymbol{h}_{\boldsymbol{i}}\right)$ for the 50 measurements versus ADV mean velocity $\left(\boldsymbol{U}_{\boldsymbol{a d v}}\right)$. Each sample contains 40 instantaneous readings. 
the velocity head displayed a high correlation with the predicted values of the ADV reference velocity ( $\left.r^{2}>0.98\right)$.

The oscillations in $h p_{i}$ resulted in velocity head samples with increasingly larger ranges, as shown in Figure 5. Outliers were present in some measurements, which were also verified in the ADV one-second recordings. Type A uncertainties propagated from this source comprised a significant portion of the expanded uncertainties in the supercritical case. In this experiment, in the higher velocities, the type A random effects were considerably greater than were those of the type B uncertainties. For example, the maximum average velocity $\left(U_{\text {pitot }}=1.98 \mathrm{~m} / \mathrm{s}\right)$ was obtained within a range of $7.4 \mathrm{~cm}$ for the corresponding $h p_{i}$ sample.

The results were less spread out when the instantaneous velocity head readings were converted into instantaneous velocities $\left(U_{\text {pitot }}\right)$, which are plotted in Figure 6. Because the velocity head is proportional to the square of the flow velocity, random variations in the latter propagated on an increasingly larger scale to $\Delta h$. This non-linear response allowed for an accurate estimation of the higher velocities, for which the Pitot tube becomes more sensitive in terms of the velocity head readings. Regarding the velocity estimation, resolution is increased as flow velocity increases. This observation was in line with the discussion about sensitivity coefficients presented in this section. Figure 6 also shows a linear regression through the origin of Pitot tube instantaneous $\left(U_{\text {pitot }_{i}}\right)$ and ADV time-averaged $\left(U_{a d v}\right)$ velocities. The best fit resulted in a high correlation $\left(r^{2}>0.98\right)$ and a calibration coefficient $(\mu)$ of 1,026 . However, performing a calibration of the Pitot tube using these data was not considered convenient because ADV velocities were also estimates that were subject to uncertainties.

For each measurement, probability distributions of the $U_{\text {pitot }_{i}}$ samples collected in the supercritical flow were analyzed statistically in order to elucidate type A uncertainties. The 29 samples were hypothesized as representative of normally distributed populations. Figure 7 shows some of the $U_{\text {pitot }_{i}}$ density histograms that were chosen arbitrarily among the supercritical measurements. These include the maximum and minimum velocities for $F r>1.3$. Ten bins were generated, and the observed densities were compared with the probability density function (PDF) of Gaussian distributions in the form of $U_{\text {pitot }_{i}} \sim N\left(U_{\text {pitot }}, s_{\text {pitot }}\right)$ for each sample. The results showed different behaviors. Although the columns appear to be well distributed about the mean, there were cases where the data were concentrated at two or more peaks. At the highest velocities, $U_{a d v}=1.750 \mathrm{~m} / \mathrm{s}$ and $U_{a d v}=1.977 \mathrm{~m} / \mathrm{s}$, the histograms reasonably approximated the Gaussian PDFs.

To advance this hypothesis, Q-Q plots of 12 representative samples were drawn (Figure 8), and the following normality tests were performed: Kolmogorov-Smirnov (KS), Shapiro-Wilk (SW), and Anderson-Darling (AD). The null hypothesis (H0) stated that the velocity samples were drawn from normally distributed populations, so that type A uncertainties observed in $h p$ and propagated to $U_{\text {pitot }}$ were caused by random variations. The resulting $\mathrm{p}$-values are given in Table 3 . Considering a significance level of 0.05 , the highlighted values shown in Table 3 indicate cases where the null hypothesis was rejected.

The Q-Q plots indicated normality for ADV velocities over $1.673 \mathrm{~m} / \mathrm{s}$, for which a strong correlation between empirical and theoretical quantiles was found although some deviations

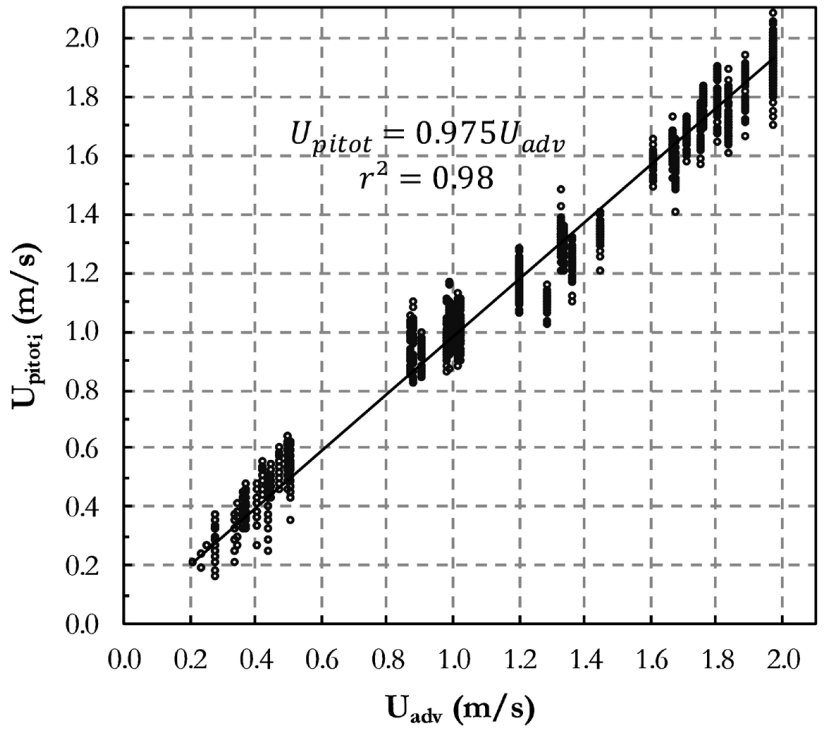

Figure 6. Samples of instantaneous Pitot tube velocity $\left(\boldsymbol{U}_{\text {pitot }_{i}}\right)$ versus ADV time-averaged velocity $\left(\boldsymbol{U}_{\boldsymbol{a d v}}\right)$.

Table 3. Normality tests p-values from Kolmogorov-Smirnov (KS), Shapiro-Wilk (SW) and Anderson-Darling (AD).

\begin{tabular}{|c|c|c|c|c|}
\hline $\begin{array}{l}U_{a d v} \\
\mathrm{~m} / \mathrm{s}\end{array}$ & $\begin{array}{l}U_{\text {pitot }} \\
\mathrm{m} / \mathrm{s}\end{array}$ & KS & SW & $\mathrm{AD}$ \\
\hline 0.871 & 0.95 & 0.08 & 0.01 & 0.00 \\
\hline 0.884 & 0.97 & 0.28 & 0.05 & 0.01 \\
\hline 0.907 & 0.91 & 0.16 & 0.02 & 0.02 \\
\hline 0.980 & 0.97 & 0.51 & 0.23 & 0.15 \\
\hline 0.990 & 0.99 & 0.72 & 0.36 & 0.25 \\
\hline 0.994 & 1.03 & 0.72 & 0.58 & 0.31 \\
\hline 1.008 & 1.02 & 0.71 & 0.08 & 0.10 \\
\hline 1.014 & 1.03 & 0.80 & 0.90 & 0.78 \\
\hline 1.017 & 0.98 & 0.80 & 0.35 & 0.52 \\
\hline 1.027 & 1.00 & 0.32 & 0.09 & 0.02 \\
\hline 1.028 & 1.00 & 0.57 & 0.31 & 0.34 \\
\hline 1.202 & 1.15 & 0.59 & 0.07 & 0.07 \\
\hline 1.203 & 1.20 & 0.71 & 0.46 & 0.50 \\
\hline 1.285 & 1.10 & 0.18 & 0.05 & 0.02 \\
\hline 1.331 & 1.32 & 0.65 & 0.19 & 0.17 \\
\hline 1.340 & 1.30 & 0.44 & 0.07 & 0.05 \\
\hline 1.367 & 1.23 & 0.91 & 0.39 & 0.51 \\
\hline 1.448 & 1.34 & 0.47 & 0.02 & 0.04 \\
\hline 1.609 & 1.57 & 0.27 & 0.05 & 0.01 \\
\hline 1.673 & 1.63 & 0.74 & 0.52 & 0.43 \\
\hline 1.675 & 1.57 & 0.36 & 0.06 & 0.11 \\
\hline 1.707 & 1.66 & 0.79 & 0.76 & 0.72 \\
\hline 1.750 & 1.69 & 0.79 & 0.63 & 0.63 \\
\hline 1.759 & 1.77 & 0.91 & 0.21 & 0.33 \\
\hline 1.805 & 1.79 & 0.66 & 0.18 & 0.25 \\
\hline 1.841 & 1.74 & 0.72 & 0.41 & 0.25 \\
\hline 1.887 & 1.82 & 0.34 & 0.31 & 0.17 \\
\hline 1.973 & 1.90 & 0.98 & 0.99 & 0.92 \\
\hline 1.977 & 1.92 & 0.96 & 0.60 & 0.69 \\
\hline
\end{tabular}

of variation of instantaneous velocities; Delta $\mathrm{U} / \mathrm{U}^{* * *}$ - Relative expanded uncertainty 

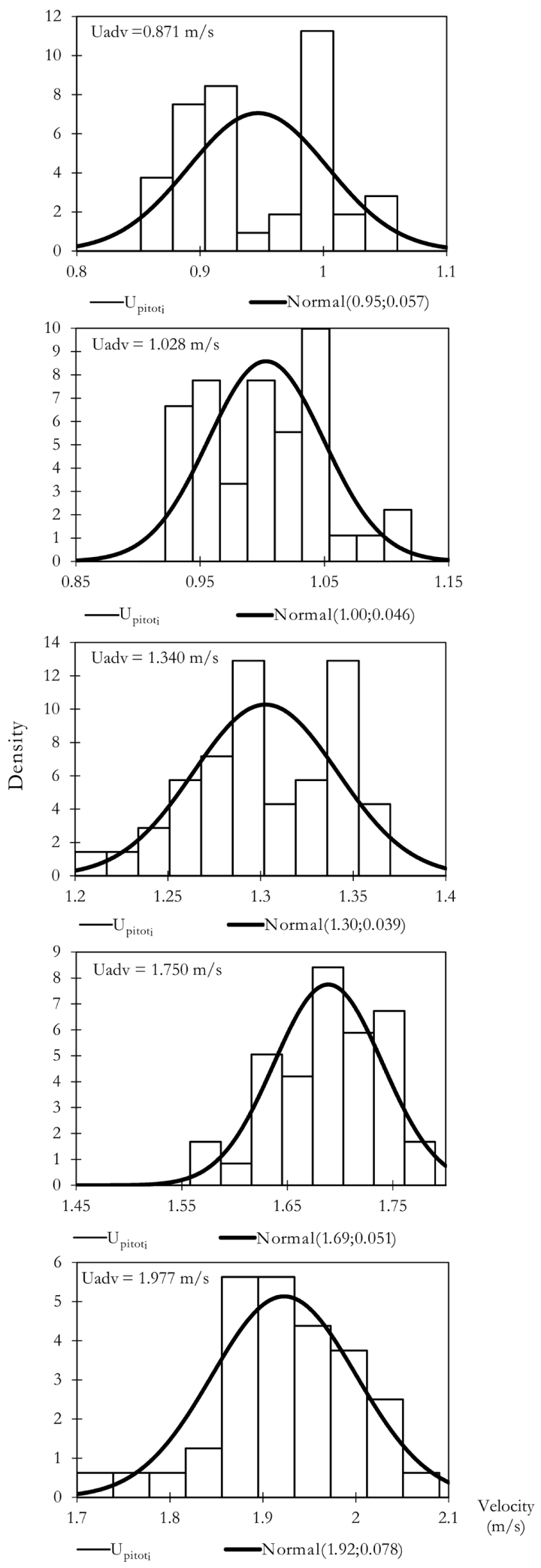

Figure 7. Density histograms of $\boldsymbol{U}_{\text {pitot }_{i}}$ for some of the measurements performed in supercritical flow. Continuous thick line represents the theoretical Gaussian distribution with observed mean and standard deviation of each sample. from this hypothesis were detected. This observation can also be verified by the results shown in Table 3; the corresponding samples passed all the normality tests. Concerning the other measurements, all samples passed the Kolmogorov-Smirnov test although it should not be used exclusively because of its low power (RAZALI; WAH, 2011; GHASEMI; ZAHEDIASL, 2012). The results of the Anderson-Darling test, which proved to be the most rigorous, indicated that $\mathrm{H} 0$ was rejected in eight samples. The results of the Shapiro-Wilk test (SHAPIRO; WILK, 1965), which was the most recommended, indicated that $\mathrm{H} 0$ was rejected in only three samples.

These results demonstrated that there was a greater tendency to verify normality hypothesis than to reject it. This verification was clarified as the mean velocity of the samples increased. As previously discussed, velocity head differentials and their variations were quantified more accurately at higher flow velocities because of the increased sensitivity of measurement. Normality tests were also performed on the measurements taken in subcritical flow, but $\mathrm{H} 0$ was rejected in virtually all the samples.

The cases in which normality was rejected, or doubtfully verified, were probably the result of insufficient reading resolution, sampling frequency, or other sources of uncertainty that were not considered in the experiment (e.g., unfiltered outliers, influence of nose geometry and probe support). Misalignment of the total head probe could also cause errors. Both the Pitot tube and ADV measurements contained uncertainties because of the effects of the angle of attack. Ackerman and Hoover (2001) showed that for a Pitot-static tube oriented at angles up to $\pm 20^{\circ}$, relative to the direction of the approaching flow, the velocity measurements were reasonably consistent. In the Pitot tube tested, the probe support ensured that the angles of attack were below this limit.

Despite these limitations, the results showed that type A uncertainties were approximately normal. This observation is a consequence of velocity unsteadiness caused by the effects of turbulent flow. Both the Pitot tube and ADV measurements were subject to these effects. Consequently, the instantaneous velocities were expected to be approximately normally distributed (ÖMER, 2011). The intensity of turbulence effects increases at points located closer to the sidewalls or the bottom of the channel. The velocity meters were placed at the same distance from these boundaries, which allowed to evaluate the results in a comparative way. A thorough discussion of the effects of turbulence is outside the scope of this paper. Although the flow was considered steady, turbulence caused pressure disturbances that influenced the instantaneous direction of the velocity vectors, thus affecting the magnitude of the longitudinal component, which was sensed by the total head probe (i.e., the $V_{x}$ component in the ADV). Consequently, each velocity series consisted in the superposition of a time-averaged velocity $\left(U_{\text {pitot }}\right.$ or $\left.U_{a d v}\right)$ and a fluctuating component. The turbulent component was estimated by the standard deviation of each series of instantaneous velocities (SANAGIOTTO et al., 2012). The effects of turbulence on the measurements were evaluated with the observed coefficients of variation $C V_{\text {pitot }}$ and $C V_{a d v}$ regarding relative turbulence intensity.

The results indicate the applicability of the prototype, which is recommended for flow velocities over $1.2 \mathrm{~m} / \mathrm{s}$, where the estimation sensitivity to uncertainties from the input variables 

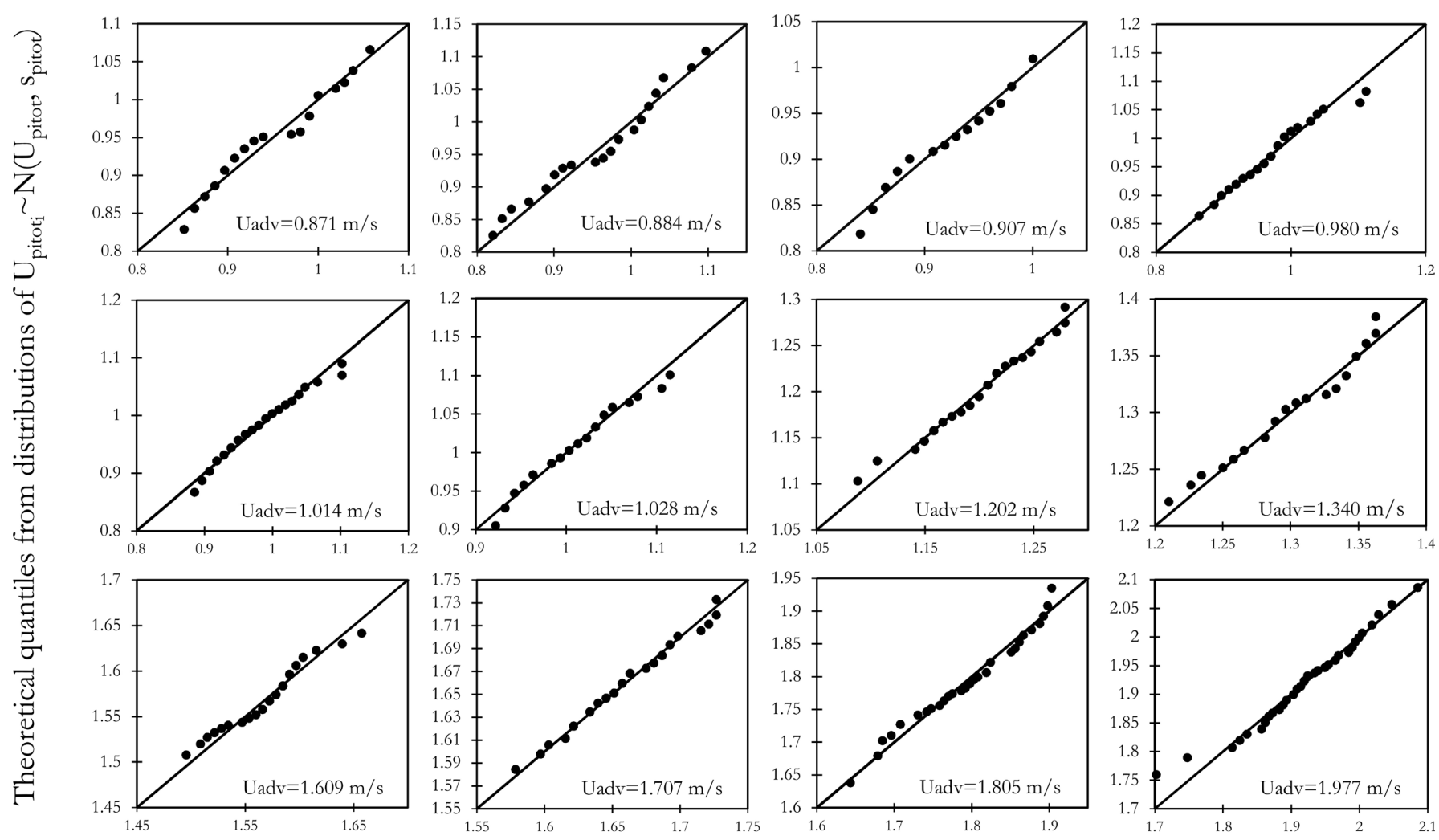

Empirical quantiles of $\mathrm{U}_{\text {pitoti }}$ samples

Figure 8. Q-Q plots of 12 representative samples of $\boldsymbol{U}_{\text {pitot }_{i}}$ in supercritical flow (29 measurements were performed in this condition).

are minimized, but should be used with caution at low velocities $(<0.6 \mathrm{~m} / \mathrm{s})$ where the measuring resolution tends to be insufficient to accurately quantify velocity heads and its instantaneous fluctuations.

\section{Performance comparison}

The one-second recordings of the measurement with the highest velocities are presented in Figure 9. The time-averaged velocities were $U_{a d v}=1.98 \mathrm{~m} / \mathrm{s}$ and $U_{\text {pitot }}=1.92 \mathrm{~m} / \mathrm{s}$. This result corresponded to a deviation of only $3 \%$ relative to the ADV mean velocity. However, there were instantaneous deviations of up to $10 \%$ in readings of $U_{a d v_{i}}$ and $12 \%$ of $U_{\text {pitot }}$, regarding their respective means. The readings were not performed simultaneously. However, because the flow conditions were maintained constant, both series of records refer to the same velocity although it was subject to uncertainties. The closeness of the means and the normal distribution clearly verified in this measurement corroborate this result.

Figure 10 presents the additional measurement performed with the ADV and the Pitot tube placed in the same cross section, as described in the section on measurement methodology. The mean values of $U_{a d v}$ and $U_{\text {pitot }}$ were $1.66 \mathrm{~m} / \mathrm{s}$ and $1.69 \mathrm{~m} / \mathrm{s}$ respectively, which indicated a deviation of only $1.8 \%$. These results did not show any significant differences from the other measurements. On the contrary, they indicated that the readings taken with both instruments in the same cross section or in different sections

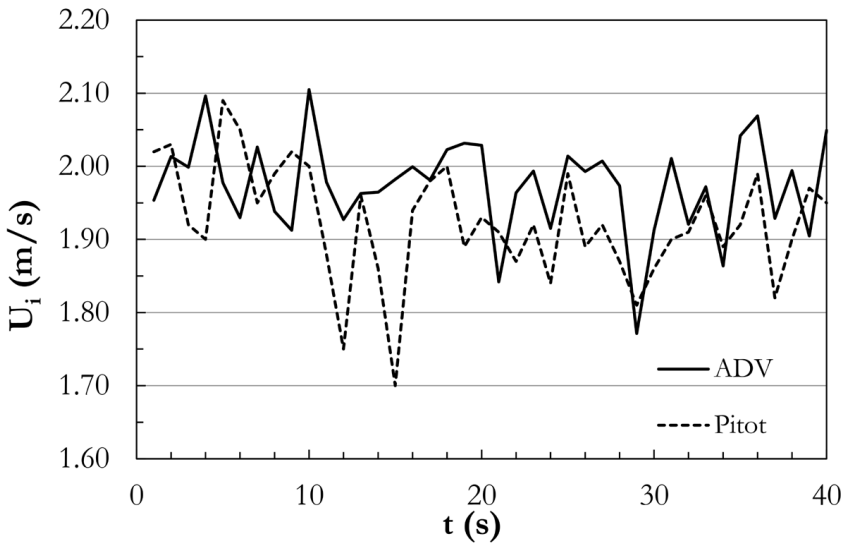

Figure 9. Comparison of instantaneous velocities from ADV $\left(\boldsymbol{U}_{\boldsymbol{a d \boldsymbol { v } _ { i }}}\right)$ and Pitot tube $\left(\boldsymbol{U}_{\text {pitot }_{i}}\right)$ in the measurement performed with the highest velocities recorded.

exhibited very close mean velocities and fluctuating components of the same order of magnitude, which demonstrated the consistency of the experimental method.

The response to turbulence was evaluated by the coefficients of variation shown in Tables 1 and $2\left(C V_{a d v}\right.$ and $\left.C V_{\text {pitot }}\right)$, which indicated the relative uncertainty (type $\mathrm{A}$ ) of the velocities measured. At lower velocities, the instantaneous fluctuations were not accurately quantified by the Pitot tube. The ADV, in contrast, showed greater sensitivity even at low velocities. This was the 


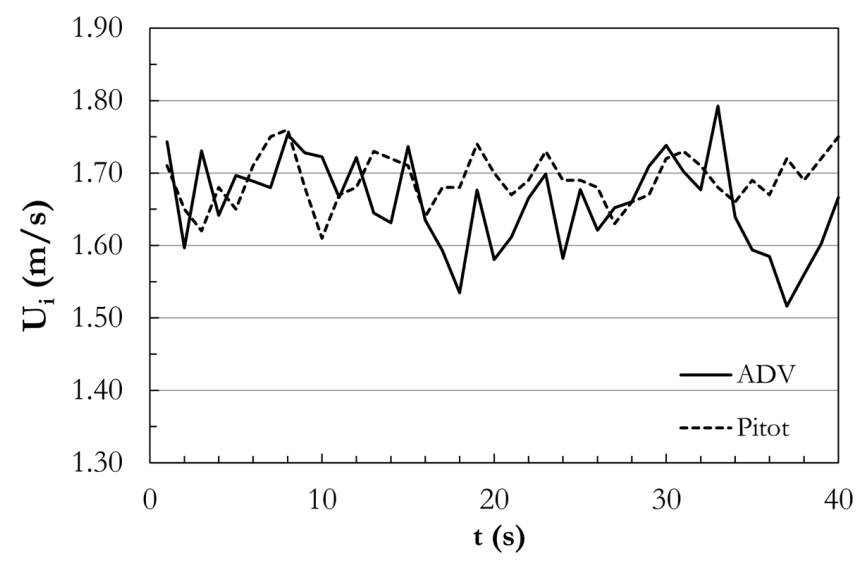

Figure 10. Comparison of instantaneous velocities from ADV $\left(\boldsymbol{U}_{\text {adv }}\right)$ and Pitot tube $\left(\boldsymbol{U}_{\text {pitot }}\right)$ in the measurement performed with both instruments at the same cross section.

case in the measurements taken in subcritical flow where $U_{a d v}$ $=0.215 \mathrm{~m} / \mathrm{s}$ and $U_{a d v}=0.251 \mathrm{~m} / \mathrm{s}$, in which the velocity heads were below the Pitot tube sensitivity so $C V_{\text {pitot }}=0$ was obtained (see Table 1). In the supercritical measurements, $C V_{a d v}$ and $C V_{\text {pitot }}$ presented similar results, especially in velocities over $1.34 \mathrm{~m} / \mathrm{s}$, of which the coefficients of variation were consistently below $5 \%$. Therefore, from the collected data, it was not possible to determine which instrument performed better related to the uncertainties propagated by turbulent fluctuations. In Figures 9 and 10, the plots show that the Pitot tube was able to provide a response to velocity fluctuations as prompt and consistent as the response of the ADV. The latter is considered a highly robust velocity meter. However, the results of the Pitot tube were similar to those of the acoustic meter, even though the Pitot tube is a much simpler instrument that does not contain sophisticated sensors and is governed by the most rudimentary of physical principles (GOLDSTEIN, 1983).

Figure 11 shows the comparison of the time-averaged velocities. The maximum difference between the estimates performed in the supercritical flow was around $15 \%$ for the measurement with $U_{a d v}=1.29 \mathrm{~m} / \mathrm{s}$ and $U_{\text {pitot }}=1.10 \mathrm{~m} / \mathrm{s}$. In the subcritical flow, the maximum difference was $21 \%$ in the measurement with $U_{a d v}=0.42 \mathrm{~m} / \mathrm{s}$ and $U_{\text {pitot }}=0.51 \mathrm{~m} / \mathrm{s}$. This difference could be the result of poor measuring resolution. It should be noted, however, that the ADV velocity lies within the $95 \%$ confidence interval propagated in this measurement $\left(U_{\text {pitot }}=0.51 \pm 0.09 \mathrm{~m} / \mathrm{s}\right)$.

The paired velocities measured by the Pitot tube and the ADV shown in Figure 11 were highly correlated $(r>0.99)$. However, this result does not imply good agreement between the two methods (GIAVARINA, 2015). A simple alternative for obtaining the degree of agreement was the Bland-Altman plot, which is shown in Figure 12 (ALTMAN; BLAND, 1983). Because the time-averaged velocities measured by both ADV and the Pitot tube contained uncertainties, the mean of the paired estimates was the best approximation of the measurand. In the Bland-Altman plot, the X-axis shows the means of the paired $U_{a d v}$ and $U_{p i t o t}$ data, denoted by $U_{\text {mean }}$. The $\mathrm{Y}$-axis represents the differences $(d)$ of these measures, which were calculated as $U_{\text {pitot }}-U_{a d v}$. This graphical approach allowed for evaluating the distribution of differences and identifying the presence of potential bias in the results.

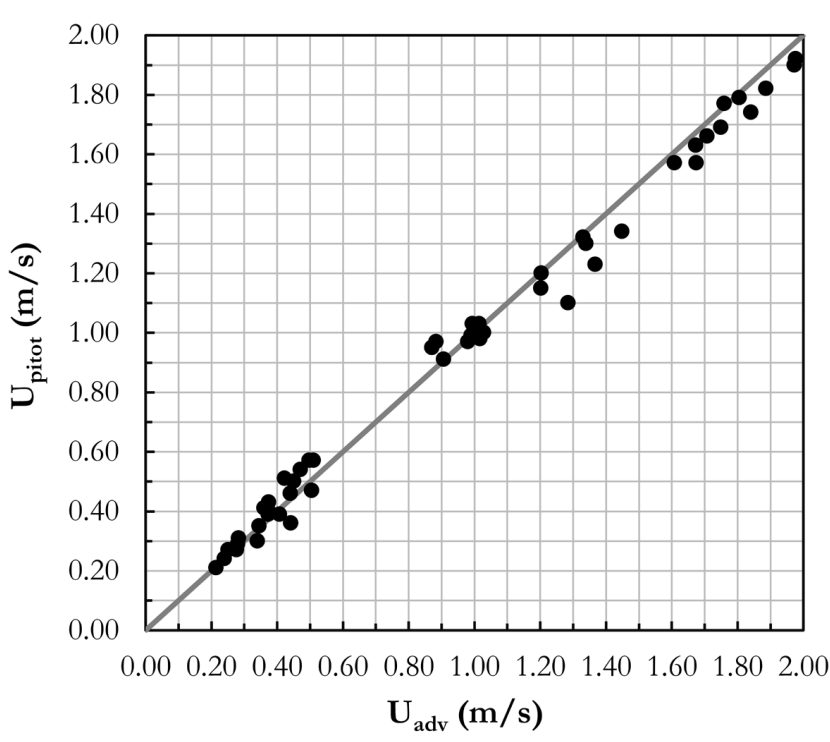

Figure 11. Time-averaged velocities from Pitot tube $\left(\boldsymbol{U}_{\text {pitot }}\right)$ versus $\operatorname{ADV}\left(\boldsymbol{U}_{\text {adv }}\right)$. Axis bisector (gray line) indicates the ideal correlation.

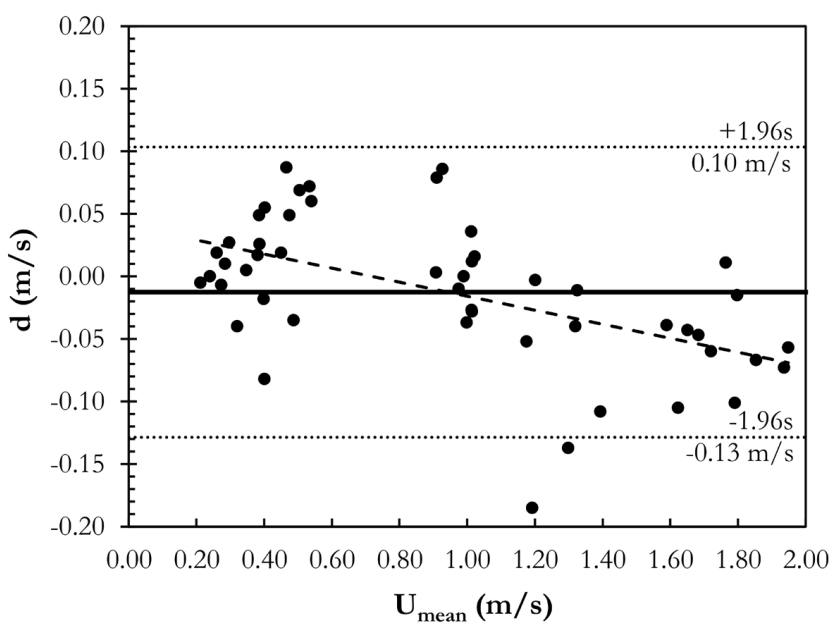

Figure 12. Bland-Altman plot for comparing mean velocity results. Differences between Pitot tube method and ADV method (d) are shown in the Y-axis and the mean of paired data $\left(\boldsymbol{U}_{\text {mean }}\right)$ in the X-axis. Continuous line represents the global average of differences $(\overline{\boldsymbol{d}})$ and dotted lines represent the $95 \%$ confidence agreement interval. Dashed line is a linear regression for $\boldsymbol{d}$ with respect to $\boldsymbol{U}_{\text {mean }}$.

A Shapiro-Wilk test was executed for the set of differences of Figure 12. The result indicated that these were normally distributed (p-value $=0.33$ ) around a global mean close to zero $(\bar{d}=-0.01 \mathrm{~m} / \mathrm{s})$. At first, this indicated the absence of bias. However, the regression line drawn in Figure 12 shows a negative trend due to the velocities over $1.0 \mathrm{~m} / \mathrm{s}$, for which the estimates of $U_{\text {pitot }}$ were smaller than $U_{a d v}$. Considering only the measurements below $1.0 \mathrm{~m} / \mathrm{s}$, there was no correlation between the differences and the means $(r<0.1)$. Moreover, the average of $d$ remained close to zero, so the initial hypothesis of the absence of bias is confirmed. The probable cause of systematic errors in the velocities over $1.0 \mathrm{~m} / \mathrm{s}$ was the 
influence of the ADV probes in the supercritical flow, which occurred at a small depth, causing an elevation of the free surface and the decrease in $U_{a d v}$. Despite this fact, the estimates remained clustered around the axis bisector (Figure 11) and the bias of velocities over $1.0 \mathrm{~m} / \mathrm{s}$, which was calculated as the mean of the corresponding differences, was only $\bar{d}=-0.06 \mathrm{~m} / \mathrm{s}$. This influence tends to be minimized in channels with larger dimensions. For a $95 \%$ confidence interval, the Bland-Altman analysis resulted in an agreement range from -0.13 to $0.10 \mathrm{~m} / \mathrm{s}$ or $\pm 15 \%$.

\section{CONCLUSIONS}

The performances of a simple Pitot tube and a Flowtracker ADV were evaluated in a laboratory channel under steady flow conditions. Based on the results of the analysis of time-averaged and instantaneous velocities, the following conclusions were drawn:

- Differential head meters with a measurement resolution lower than or equal to $10^{-3} \mathrm{mH} 2 \mathrm{O}$ are not suitable for low velocities $(\leq 0.6 \mathrm{~m} / \mathrm{s})$, but they can perform accurately in measurements over $1.2 \mathrm{~m} / \mathrm{s}$ where the propagation of uncertainties from head readings is minimized.

- Open-channel differential head meters are susceptible to disturbances on the free surface. To minimize the uncertainties caused by this source, it is recommended that the static heads be sampled at a high frequency, as it was done for the instantaneous total heads in the present experiment.

- In measuring the instantaneous fluctuations caused by turbulent flow, the more sophisticated and expensive acoustic meter performed similar to the prototype Pitot tube. Both instruments showed turbulent fluctuation components of the same magnitude in the velocities of the supercritical flow.

- The time-averaged velocities obtained by the Pitot tube did not differ substantially from those obtained by the ADV. Considering that the prototype was not calibrated and that the measurement process was subject to errors in the operation, the agreement range of $15 \%$ was reasonable. This range is expected to be reduced in further higher flow velocities.

Differential head meters have potential as an alternative technique for measurements in open channels. Pitot devices are minimally affected by inertia and suitable for high-velocity water flows where instantaneous fluctuations require a high sampling frequency. In addition, the Pitot tube can be developed with a small-sized geometry that allows minimal influence in the velocity field when it is inserted into the flow.

Despite the encouraging results obtained in the laboratory, it is evident that the tested instrument needs to be improved before it is deployed in the field. The implantation of a static head probe and a pressure transducer is recommended to overcome the difficulty in measuring the heads, which was the main operational challenge in the present experiment. Another improvement is related to the procedure of aligning the probe axis in the flow direction, which is also necessary in conventional meters. Self-orientation could be achieved by the proper hydrodynamic adaptation of the device. The presence of sediments in the water, however, continues to challenge the application of such instruments in certain flows.

\section{REFERENCES}

ACKERMAN, J. D.; HOOVER, T. M. Measurement of local bed shear stress in streams using a Preston-static tube. Limnology and Oceanography, v. 46, n. 8, p. 2080-2087, 2001. http://dx.doi. org/10.4319/lo.2001.46.8.2080.

ALTMAN, D. G.; BLAND, J. M. Measurement in medicine: the analysis of method comparison studies. Journal of the Royal Statistical Society. Series D (The Statistician), v. 32, n. 3, p. 307-317, 1983. http:/ / dx.doi.org/10.2307/2987937.

ASKARI, Z.; AFZALIMEHR, H.; SINGH, V. P.; FATTAHI, R. Prediction of flow velocity near inclined surfaces with varying roughness. International Journal of Hydraulic Engineering, v. 4, n. 1, p. 1-9, 2015. http://dx.doi.org/10.5923/j.ijhe.20150401.01.

BROWN, G. O. Henry Darcy's perfection of the Pitot tube. In: SYMPOSIUM TO HONOR HENRY PHILIBERT CASPARD DARCY, 2003, Philadelphia. Proceedings... New York: American Society of Civil Engineers, 2003. p. 14-23. http://dx.doi. org/10.1061/40683(2003)3.

DURGA RAO, K. H. V.; PILLAI, C. R. S. Study of flow over side weirs under supercritical conditions. Water Resources Management, v. 22, n. 1, p. 131-143, 2008. http://dx.doi.org/10.1007/s11269007-9153-4.

FINNEMORE, E.; FRANZINI, J. Fluid mechanics with engineering applications. 10. ed. Boston: McGraw-Hill, 2002.

FONSTAD, M. A.; REICHLING, J. P.; DE GRIFT, J. W. The transparent velocity-head rod for inexpensive and accurate measurement of stream velocities. Journal of Geoscience Education, v. 53, n. 1, p. 44-52, 2005. http://dx.doi.org/10.5408/1089-999553.1.44.

FOX, R. W.; MCDONALD, A. T. Introdução à mecânica dos fluidos. 5. ed. Rio de Janeiro: Livros Técnicos e Científicos, 2001.

FULFORD, J. M. Effects of pulsating flow on current meter performance. In: INTERNATIONAL WATER RESOURCES ENGINEERING CONFERENCE, 1., 1995, San Antonio. Proceedings... New York: American Society of Civil Engineers, 1995. p. 917-921. v. 1.

GHASEMI, A.; ZAHEDIASL, S. Normality tests for statistical analysis: a guide for non-statisticians. International Journal of Endocrinology and Metabolism, v. 10, n. 2, p. 486-489, 2012. PMid:23843808. http:// dx.doi.org/10.5812/ijem.3505. 
An alternative method for measuring velocities in open-channel flows: perfomance evaluation of a Pitot tube compared to an acoustic meter

GIAVARINA, D. Understanding bland altman analysis. Biochemia Medica, v. 25, n. 2, p. 141-151, 2015. PMid:26110027. http://dx.doi. org/10.11613/BM.2015.015.

GOLDSTEIN, R. J. Fluid mechanics measurements. New York: New York Hemisphere, 1983.

JOHANSEN, J. L. Quantyfing water flow within aquatic ecosystems using load cells: a profile of currents experienced by coral reef organisms around Lizard Island, Great Barrier Reef, Australia. PLoS One, v. 9, n. 1, p. 1-9, 2014. PMid:24421878. http://dx.doi. org/10.1371/journal.pone.0083240.

JOINT COMMITTEE FOR GUIDES IN METROLOGY JCGM. Evaluation of measurement data - Guide to the expression of uncertainty in measurement. Sèvres: JCGM, 2008.

LE COZ, J.; CAMENEN, B.; PEYRAR, X.; DRAMAIS, G. Uncertainty in open-channel discharges measured with the velocityarea method. Flow Measurement and Instrumentation, v. 26, p. 18-19, 2012. http://dx.doi.org/10.1016/j.flowmeasinst.2012.05.001.

MAGIRL, C. S.; GARTNER, J. W.; SMART, G. M.; WEBB, R. $\mathrm{H}$. Water velocity and the nature of critical flow in large rapids on the Colorado River, Utah. Water Resources Research, v. 45, n. 5, p. n/a, 2009. http://dx.doi.org/10.1029/2009WR007731.

MARCHANT, R.; STEVENS, T.; CHOUKRUN, S.; COOMBES, G.; SANTAROSSA, M.; WHINNEY, J.; RIDD, P. A Buyoant tethered sphere for marine current estimation. IEEE Journal of Oceanic Engineering, v. 39, n. 1, p. 2-9, 2014. http://dx.doi. org/10.1109/JOE.2012.2236151.

MUSTE, M.; LEE, K.; BERTRAND-KRAJEWSKI, J. L. Standardized uncertainty analysis for hydrometry: a review of relevant approaches and implementation examples. Hydrological Sciences Journal, v. 57, n. 4, p. 643-667, 2012. http://dx.doi.org/1 $0.1080 / 02626667.2012 .675064$.

NIKORA, V. I.; SMART, G. M. Turbulence characteristics of New Zealand Gravel-Bed Rivers. Journal of Hydraulic Engineering, v. 123, n. 9, p. 764-773, 1997. http://dx.doi.org/10.1061/(ASCE)07339429(1997)123:9(764).

ÖMER, K. Distribution of turbulence statistics in open-channel flow. International Journal of the Physical Sciences, v. 6, n. 14, p. 34263436, 2011. http://dx.doi.org/10.5897/IJPS11.704.

RAZALI, N. M.; WAH, Y. B. Power comparisons of Shapiro-Wilk, Kolmogorov-Smirnov, Lilliefors and Anderson-Darling tests. Journal of Statistical Modeling and Analytics, v. 2, n. 1, p. 21-33, 2011.

REHMEL, M. Application of acoustic doppler velocimeters for streamflow measurements. Journal of Hydraulic Engineering, v. 133, n.
12, p. 1433-1438, 2007. http:/ / dx.doi.org/10.1061/(ASCE)07339429(2007)133:12(1433).

REPLOGUE, J.; WAHLIN, B. Pitot-static tube system to measure discharge from wells. Journal of Hydraulic Engineering, v. 126, n. 5, p. 335-346, 2000. http://dx.doi.org/10.1061/(ASCE)07339429(2000)126:5(335).

SANAGIOTTO, D. M.; PINHEIRO, A. N.; MARQUES, M. G. Caracterização de velocidades médias e padrões de turbulência do escoamento em escadas para peixes por bacias sucessivas com orifícios de fundo. Revista Brasileira de Recursos Hídricos, v. 17, n. 2, p. 181-192, 2012. http://dx.doi.org/10.21168/rbrh.v17n2.p181-192.

SHAPIRO, S. S.; WILK, M. B. An analysis of variance test for normality (complete samples). Biometrika, v. 52, n. 3-4, p. 591-611, 1965. http://dx.doi.org/10.1093/biomet/52.3-4.591.

SMART, G. M. A P.O.E.M. on the Waiho (electronic gauging of rivers). Journal of Hydrology. New Zealand, v. 30, n. 1, p. 37-44, 1991.

SONTEK; YSI INCORPORATED. Flowtracker handled ADV technical manual. San Diego, 2007.

VOULGARIS, G.; TROWBRIDGE, J. H. Evaluation of Acoustic Doppler Velocimeter (ADV) for turbulence measurements. Journal of Atmospheric and Oceanic Technology, v. 15, n. 1, p. 272-289, 1998. http://dx.doi.org/10.1175/1520-0426(1998)015<0272:EOTA $\mathrm{DV}>2.0 . \mathrm{CO} ; 2$.

WORLD METEOROLOGICAL ORGANIZATION - WMO. Manual on Stream Ganging. Geneva, 2010a. v. 1 - Fieldwork, WMO$\mathrm{N}^{\mathrm{o}} 1044$.

WORLD METEOROLOGICAL ORGANIZATION - WMO. Manual on Stream Gauging. Geneva, 2010b. v. 2 - Computation of Discharge. WMO-No 1044.

\section{Authors contributions}

Arlan Scortegagna Almeida conducted the experiment and developed all data analysis, including statistical analysis and discussion of the results. He wrote the paper.

Vladimir Caramori Borges de Souza was the advisor professor who conceived the experiment and provided suggestions regarding data analysis and results discussion. He revised the writing of the paper. 